\title{
Pain Control with Splanchnic Neurolysis in Pancreatic Cancer Patients Unresponsive to Celiac Plexus Neurolysis
} This article was published in the following Dove Press journal:
Journal of Pain Research

Background/Aims: In most instances of abdominal pain associated with pancreatic cancer, pain may become refractory to increasing doses of narcotics. Celiac plexus neurolysis represents an option; however, altered celiac plexus anatomy may render this treatment infeasible or ineffective, where splanchnic nerve neurolysis may represent another option. This study aimed to investigate the outcomes of splanchnic neurolysis in pancreatic cancer patients not responsive to celiac plexus neurolysis.

Patients and Methods: Among all 84 patients who underwent celiac plexus neurolysis for pancreatic cancer pain during the study period, 34 patients did not respond and underwent splanchnic nerve neurolysis under fluoroscopic guidance and thus included in this retrospective study. Stage IV, III, and II disease was present in $38.2 \%, 47.1 \%$, and $14.7 \%$ of the patients. During the study, $88.2 \%$ were receiving chemotherapy, whereas none were on radiotherapy. Data for daily narcotic dose equivalents and Visual Analogue Scale (VAS) scores during outpatient visits at baseline, 2 weeks, 2 months, and 3 months were extracted. Results: Pain response rates were $76.5 \%, 84.4 \%$, and $71.0 \%$, at 2 weeks, 2 months, and 3 months, respectively. A significant and dramatic reduction was seen in VAS scores at 2 weeks $(2.8 \pm 1.2$ versus $6.3 \pm 1.1, \mathrm{p}<0.001)$, and this significant decline was maintained for 3 months. Similarly, a significant and dramatic reduction was seen in daily narcotic need at 2 weeks $(20.8 \pm 32.9$ versus $93.4 \pm 86.2 \mathrm{mg}, \mathrm{p}<0.001)$, which was also maintained during the 3-month follow-up. The procedure was generally well tolerated.

Conclusion: Findings of this study suggest that splanchnic neurolysis represents a durable and effective option for pain control in pancreatic cancer patients in whom the neurolysis of the celiac plexus is ineffective. However, these conclusions refer to only preliminary singlecenter results in a selected patient group; thus, further large studies are warranted.

Keywords: pancreatic cancer, pain control, splanchnic neurolysis, celiac plexus neurolysis

\section{Plain Language Summary}

Pain is a common symptom in pancreatic cancer. It is usually difficult to control and has a negative impact on the lives of the patients. In most instances, pain may even become refractory to increasing doses of narcotics, which may lead to narcotics-related side effects.

Splanchnic nerve carries sensory signals from the organs and thus has a role in the transmission of pain signals to the central nervous system in pancreatic cancer. In this study, we examined the effects of splanchnic neurolysis (chemical degeneration of the nerve) on the relief of pancreatic cancer pain among 34 patients in whom other options failed.
Gayrettepe Florence Nightingale Hospital,

Department of Anesthesiology and

Reanimation, Istanbul, Besiktas 34349,

Turkey

Tel +905324273310

Emailsavatc@gmail.com
Journal of Pain Research 2020:13 2023-203|

2023 
A dramatic reduction was seen in pain intensity and narcotic need shortly after the treatment, which was maintained during the 3-month follow-up. In addition, the procedure was well tolerated.

We believe that splanchnic neurolysis treatment represents a durable and effective option for pain control in pancreatic cancer patients in whom other treatments are ineffective.

\section{Introduction}

Pancreatic cancer is a treatment-resistant malignancy that represents the seventh most frequent cause of cancer deaths in the developed world. ${ }^{1}$ Abdominal pain associated with pancreatic cancer is a common complication leading to reduced patient performance and survival. ${ }^{2,3}$ Pain is the third most common symptom (72\%) after weight loss $(92 \%)$ and jaundice $(82 \%)$ in patients with cancer of the head of pancreas, while it is the second most common symptom occurring in $87 \%$ of the patients in cancers involving the corpus and tail. ${ }^{2,3}$

As stated in the cancer pain ladder developed by the World Health Organization (WHO), opioid-containing systemic analgesics are used as the initial choice of therapy for the management of pain associated with pancreatic cancer. $^{4,5}$ However, in most instances, pain may even become refractory to increasing doses of narcotics, which may lead to opioid-related side effects. ${ }^{6-8}$

Neurolytic block is an invaluable therapeutic approach for managing patients with resistant pain, and particularly in those with advanced cancer. ${ }^{9-14}$ Neurolytic interventions can be performed using neurolytic agents such as phenol or alcohol, which block pain signals in pain-eliciting nervous tissues by causing Wallerian degeneration. Neurolysis of the celiac plexus is known to be effective for the management of pain due to upper gastrointestinal malignancies. ${ }^{9-14}$ Most studies and reviews of celiac plexus block showed excellent pain control in carefully selected patients, with additional advantages of reduced opioid burden and increased quality of life. ${ }^{9-14}$ On the other hand, a number of factors such as surgery involving the gastrointestinal system, underlying malignancy, or enlarged celiac lymph nodes may alter the normal anatomy of the celiac plexus, leading to reduced access to celiac ganglia or inadequate diffusion of the neurolytic agents into tissues. ${ }^{15,16}$ Therefore, in painful malignancies affecting the upper abdomen infeasible for neurolysis of the celiac plexus due to distorted anatomy of the celiac lymph nodes as shown by radiological imaging, successful results have been attained by splanchnic neurolysis performed under fluoroscopic guidance. ${ }^{17}$ Major indications for the neurolysis of the celiac plexus include tolerance to narcotic agents and the need to avoid their side effects. When unsuccessful neurolysis of the celiac plexus is complicated by the presence of narcotic tolerance and side effects, management of the pain due to pancreatic cancer becomes even more challenging.

Under these circumstances, neurolysis of the splanchnic nerve may serve as a viable alternative when the traditional celiac plexus neurolysis fails, due to the distant location of this nerve from the primary anatomical source of the pain (ie the pancreas), site of surgery, or enlarged lymph nodes. Furthermore, some studies even suggested a higher efficacy of splanchnic neurolysis than celiac plexus neurolysis. ${ }^{18}$ Also, radiofrequency ablation of the splanchnic nerves is another therapeutic option, although it is rarely used. ${ }^{19}$

This study investigated whether splanchnic neurolysis may be a therapeutic option for patients with pancreatic cancer pain in whom neurolysis of the celiac plexus has failed.

\section{Patients and Methods}

\section{Patients}

A total of 34 patients who attended to our unit between March 2015 and August 2019 and underwent splanchnic nerve neurolysis under fluoroscopic guidance due to insufficient pain control after celiac plexus neurolysis were included in this study. During that period, a total of 84 celiac plexus neurolysis were done for pain due to pancreatic cancer, with a response rate of $59.5 \%$. All patients that did not respond $(n=34)$ underwent splanchnic neurolysis $(40.5 \%)$. In our clinic, a total of 163 pancreatic cancer patients underwent splanchnic neurolysis procedure for pancreatic cancer during that period, 34 for inadequate pain control after celiac neurolysis (patients in this study), the remaining were done as first-line treatment.

Patients' medical records were evaluated retrospectively. Inclusion criteria were as follows: a diagnosis of pancreatic cancer, persistent and moderate to severe upper abdominal pain (Visual Analogue Scale (VAS) score $\geq 4$ ), unresponsive to opioids or intolerable opioid-related side effects, and failure of a single attempt of celiac plexus neurolysis defined as insufficient pain control in up to 2-3 weeks after the intervention.

Transdermal therapeutic system patch releasing 25 to $100 \mu \mathrm{g}$ of fentanyl per hour in combination with adjuvant analgesics was the commonly used medical treatment. Opioid therapy failure was defined as the inability to 
control pain with maximum of 100 micrograms/hour fentanyl dose or its equivalent, or unable to receive efficient opioid dose due to intolerable side effects. Those with systemic disorders and infections, coagulation disorders, severe spinal pathology, or clinically significant cardiac or pulmonary conditions were excluded. The study protocol was approved by the local ethics committee (Demiroglu Bilim University, Ethics Committee for Clinical Research; date, December 16, 2019; no, 44140529/482) and informed consent was not compelled due to the retrospective nature of the study. The study was conducted in accordance with the Declaration of Helsinki and all patient data accessed complied with relevant patient data protection and privacy regulations.

Demographic and other descriptive data as well as required daily narcotic doses and VAS scores during outpatient visits at baseline, 2 weeks, 2 months, and 3 months were extracted. Possible side effects after the intervention were examined, including hypotension, increased frequency of defecation, neuritis, pneumothorax, and other adverse reactions. Radiotherapy and chemotherapy status were recorded. Primary and secondary outcome was the change in VAS scores and daily narcotic doses (morphine equivalent) over time, respectively.

\section{Statistical Analysis}

Data were analyzed using SPSS (Statistical Package for Social Sciences) software version 21 (IBM Corp.; Armonk, NY, USA). Descriptive data are presented in number (percentage) or mean \pm standard deviation, where appropriate. A longitudinal mixed model was used to examine the significance of changes in VAS scores and required daily narcotic doses over time. A "compound symmetry" and "unstructured" covariance structure was used for VAS and narcotic dose, respectively, since respective structures provided the best model fit with the lowest Akaike Information Criterion (AIC) value. Post hoc comparisons of VAS and daily narcotic dose between different time points were done with Bonferroni correction. Twosided $\mathrm{p}$ values $<0.05$ were considered an indication of statistical significance.

\section{Results}

\section{Patient Characteristics}

Distribution of patients by pancreatic cancer stage was as follows: Stage IV, 13 patients (38.2\%); Stage III, 16 patients (47.1\%); Stage II, 5 patients (14.7\%). Table 1 shows patient
Table I Demographical and Clinical Characteristics of the Patients at Baseline

\begin{tabular}{|l|l|}
\hline Characteristics & $\mathbf{n = 3 4}$ \\
\hline Age, $\mathrm{y}($ mean $\pm \mathrm{SD})$ & $58.4 \pm 10.8$ \\
Male gender & $16(47.1 \%)$ \\
$\mathrm{BMI}, \mathrm{kg} / \mathrm{m}^{2}$ (mean $\left.\pm \mathrm{SD}\right)$ & $23.1 \pm 3.5$ \\
Previous operation & $8(23.5 \%)$ \\
Recurrent disease & $8(23.5 \%)$ \\
Narcotic intolerance & $27(79.4 \%)$ \\
Local/lymphatic extension & $29(85.3 \%)$ \\
Distant metastasis* & $13(38.2 \%)$ \\
\hline
\end{tabular}

Notes: *All were liver metastasis. Unless otherwise stated data presented as $\mathrm{n}(\%)$. Abbreviations: SD, standard deviation; BMI, body mass index.

characteristics at baseline. Majority of the patients had a history of narcotic intolerance (79.4\%). Only less than onequarter of patients had recurrent disease at the time of study initiation. Most of the patients had local extension and/or lymphatic involvement at baseline $(85.3 \%)$, whereas less than half had liver metastasis (38.2\%). During the study period, 30 patients $(88.2 \%)$ received chemotherapy. These patients received chemotherapy courses at the time of celiac plexus neurolysis, and/or splanchnic neurolysis, and/or during the follow-up period (thus during the study). Four patients had received chemotherapy before celiac plexus neurolysis, but not during the study. Eight patients (23.5\%) had received radiotherapy before celiac plexus neurolysis. Thus, none of the patients received radiotherapy during the study. Although all celiac plexus neurolysis procedures could be completed successfully from technical point of view, patients did not respond clinically.

\section{Technique for Celiac Plexus Neurolysis}

Celiac plexus neurolysis was done using classical retrocrural double-needle technique. Under fluoroscopy guidance, each of the two $15 \mathrm{~cm} 18 \mathrm{G}$ needles was placed to the left and right anterolateral areas of the first lumbar vertebral body, respectively. Following a test injection with $2 \mathrm{~mL}$ of $2 \%$ lidocaine to both sides, $10 \mathrm{~mL}$ of $100 \%$ alcohol plus $5 \mathrm{~mL}$ of $2 \%$ lidocaine were injected to each side for neurolysis.

\section{The Technique for Splanchnic Nerve Neurolysis}

The entire procedure was performed under aseptic conditions with X-ray guidance at the operation theater. Patients fasted for 6 hours prior to the procedure, and a $20 \mathrm{G}$ intravenous cannula was placed. Before the procedure, $500 \mathrm{~mL}$ of 
physiological saline was administered intravenously. The patient was positioned in the prone position on the surgical table with the chest supported using a pillow, in order to reverse the thoracolumbar lordosis and to increase the distance between the superior iliac spine and the chest cage. The patient was monitored using electrocardiography, noninvasive blood pressure measurements, and pulse oximetry in accordance with the standards proposed by the American Association of Anesthesiologists. Physiological saline infusion was initiated. T12 was visualized with fluoroscopy, and the distance between the transverse processes and corpus of the vertebra was appropriately adjusted by rotating the c-arm 20-30 degrees. A 22G $15 \mathrm{~cm}$ Chiba needle (Cook Medical Inc., Bloomington, IN, USA), which would be used for injections, was inserted, and directed to the anterolateral border of T12 vertebra under fluoroscopy guidance. This procedure was done for the left and right sides separately.

T12 vertebra and the final position of the needles were ascertained under fluoroscopy guidance on anteroposterior and lateral views. The absence of blood or liquid was ascertained by a gentle aspiration. Then, the radioopaque material was administered, and its diffusion is confirmed with fluoroscopy. For splanchnic nerve neurolysis, $6 \%$ phenol solution was administered to both sides at a dose of 5 to $8 \mathrm{~mL}$ using the Chiba needle (Cook Medical Inc., Bloomington, IN, USA). Figure 1 shows fluoroscopic views during the procedure.

The procedure lasted 30 minutes, and the recovery period lasted 10 minutes since conscious sedation was used. After the procedure, patients were kept under medical observation for 4 to 6 hours to monitor possible hemodynamic complications. Regular administration of analgesics was initiated after the procedure using the WHO criteria, when necessary.

\section{Response Rates to Splanchnic Neurolysis}

Majority of the patients responded to splanchnic neurolysis (VAS score $<4$ ), response rates were 76.5\% (26/34), $84.4 \%$ (28/33), and 71.0\% (22/31), at 2 weeks, 2 months, and 3 months, respectively. At 2 weeks, 2 months, and 3 months, $26.5 \%$ (9/34), 30.3\% (10/33), and 29.0\% (9/31) of patients did not require narcotics.

\section{Changes in Visual Analogue Scale Scores Over Time}

Figure 2 shows the changes in VAS scores over time (at baseline and at 2 weeks, 2 months and 3 months). A significant change in VAS scores was evident over time $(\mathrm{p}<0.001$ for global difference). A significant and dramatic reduction was seen at 2 weeks $(2.8 \pm 1.2$ versus $6.3 \pm 1.1, \mathrm{p}<0.001)$. Similarly, VAS scores were significantly lower at 2 months and 3 months when compared to baseline $(2.6 \pm 1.0$ and $2.9 \pm 1.2$ versus $6.3 \pm 1.1, p<0.001$ for both). However, scores at 2 weeks, 2 months and 3 months did not differ significantly ( $p>0.05$ for all comparisons). Thus, the significant decline in VAS scores was maintained during the 3-month follow-up period.

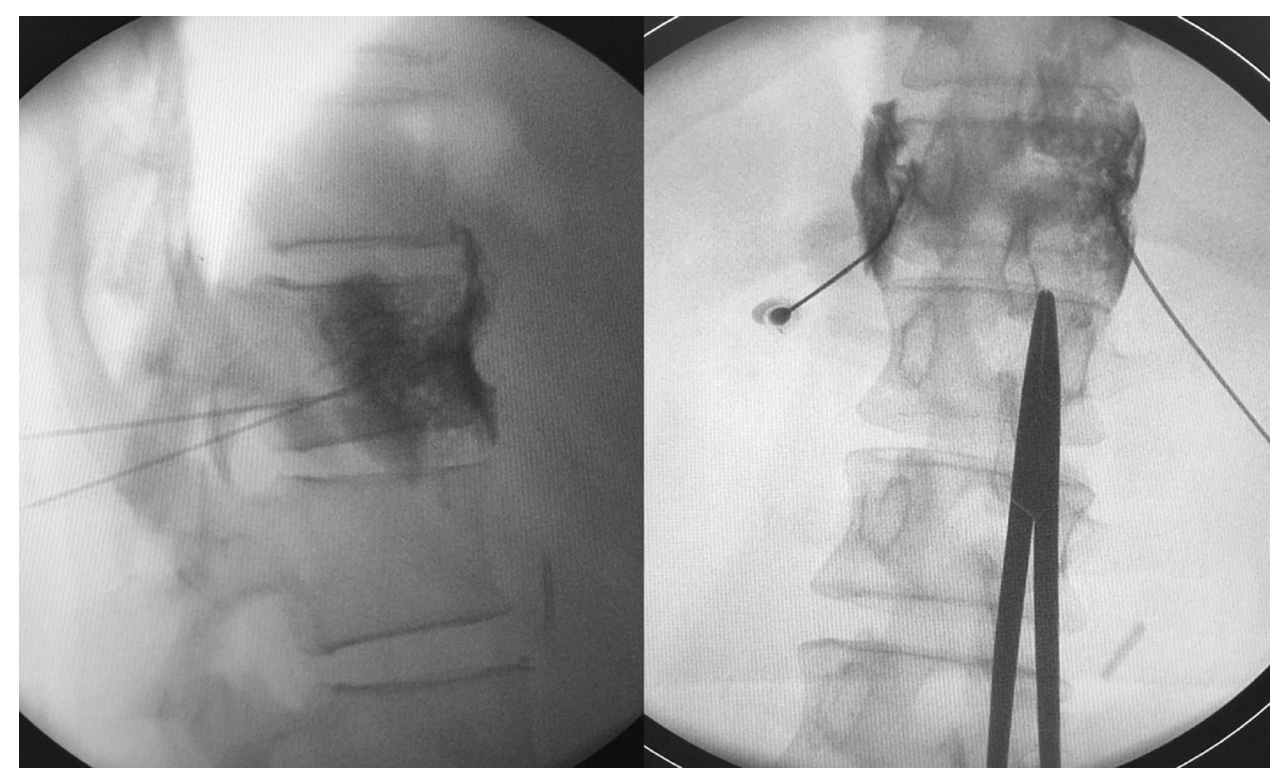

Figure I Lateral (left) and anteroposterior fluoroscopic views during the procedure. Positions of the two needles and spread of radiopaque material are seen in both views. 


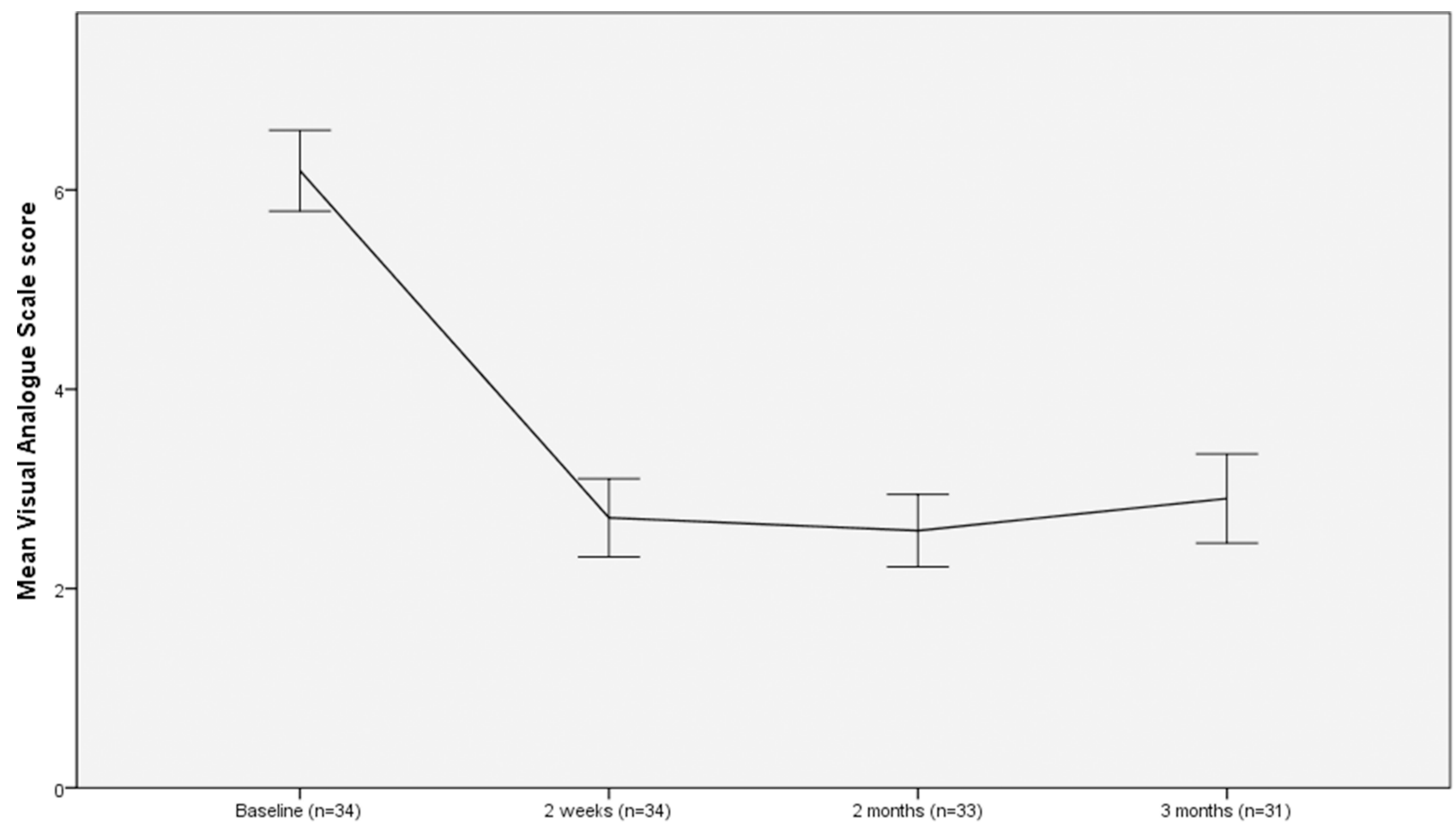

Figure 2 Changes in mean Visual Analogue Scale scores of 34 patients over time (at baseline, 2 weeks, 2 months, and 3 months). Error bars indicate $95 \%$ confidence intervals.

\section{Changes in Narcotic Requirement Over Time}

Figure 3 shows the changes in the required daily narcotic dose (morphine equivalent) over time. A significant change in doses was evident $(p<0.001)$ with a pattern similar to the changes in VAS scores. A significant and dramatic reduction was seen at 2 weeks $(20.8 \pm 32.9$ versus $93.4 \pm 86.2 \mathrm{mg}, \mathrm{p}<0.001)$. Similarly, VAS scores were significantly lower at 2 months and 3 months when compared to baseline $(24.6 \pm 52.6$ and $28.2 \pm 60.4$ versus 93.4 $\pm 86.2 \mathrm{mg}, \mathrm{p}<0.001$ and $\mathrm{p}=0.001$, respectively). However, scores at 2 weeks, 2 months and 3 months did not differ significantly ( $>0.05$ for all comparisons). Thus, a dramatic reduction in daily narcotic dose requirement was evident and maintained during the 3-month period.

\section{Safety}

No procedure-related complication was seen during the study period except for a suspected neuritis characterized by back pain developed after the procedure, which spontaneously resolved in 2 weeks. The procedure was generally well tolerated. An acceptable increase in defecation frequency was seen in nine patients, and one of them required intravenous fluids for 1 week. Hypotension developed in 14 patients, which responded to intravenous fluid administration and resolved on the same day.

\section{Discussion}

Our results showed that splanchnic neurolysis is an effective therapeutic approach to control pain and reduce narcotic use for at least 3 months in pancreatic cancer patients following a failed attempt of celiac plexus neurolysis for pain control. To the best of our knowledge, this is the first study to evaluate splanchnic neurolysis in this patient group.

Various methods have been described to achieve neurolysis at the celiac plexus and splanchnic nerves. Such methods can be performed under fluoroscopy, ultrasound, endoscopy, as well as computerized tomography guidance. Neurolysis of retrocrural splanchnic nerves under fluoroscopy guidance is a commonly used strategy, and we used the same technique in our study. ${ }^{20}$ Chemical neurolysis is generally achieved using alcohol $(50 \%$ to $100 \%)$ or phenol ( $5 \%$ to $10 \%$ ) that provides effective pain control for 3 to 6 months. ${ }^{21,22}$ No significant difference in efficacy between alcohol and phenol was reported, while the risk of neuritis, which is one of the major side effects of this procedure, was found to be lower with phenol use. ${ }^{20,23}$ Therefore, we preferred $6 \%$ phenol solution for our patients. 


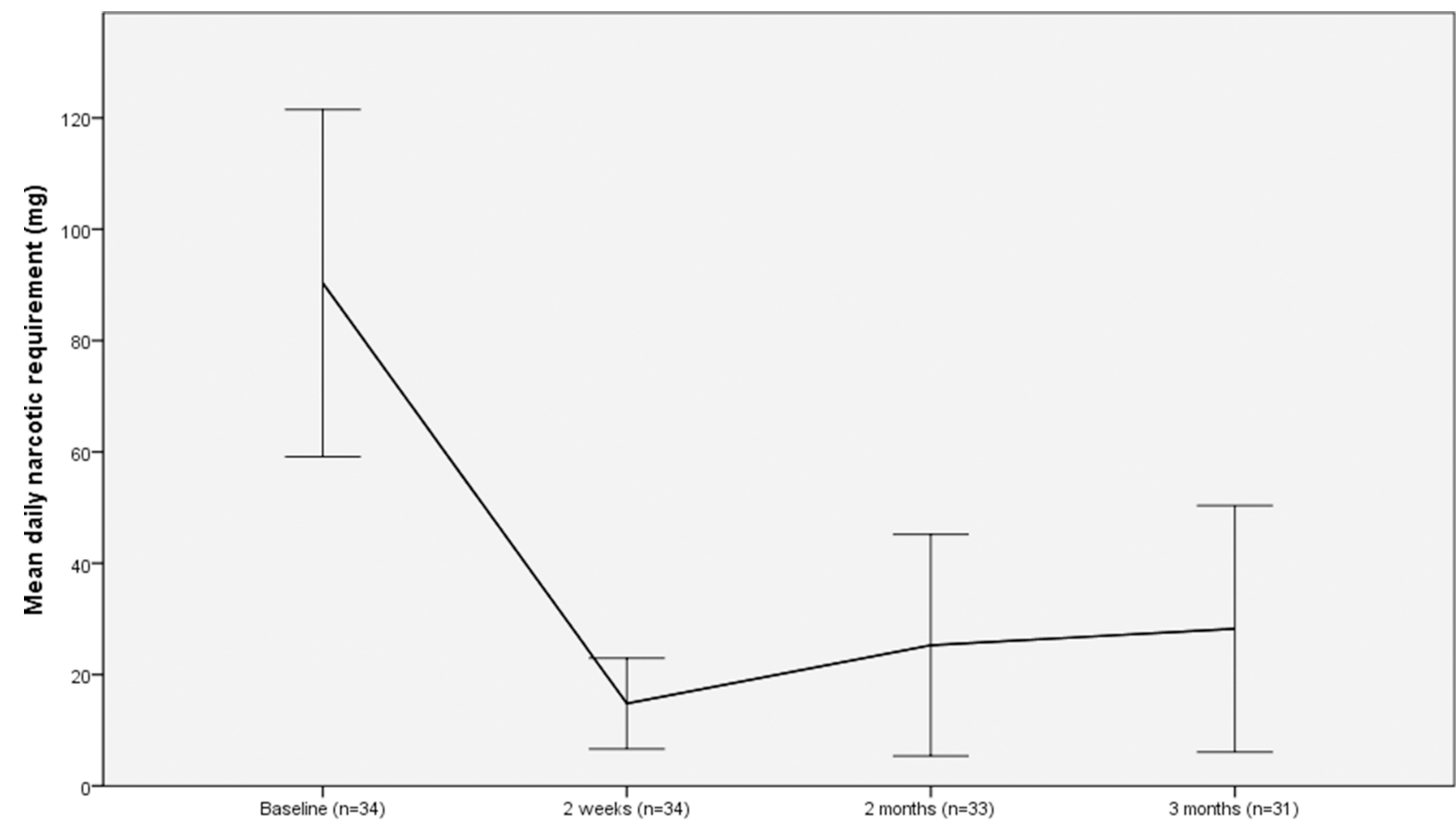

Figure 3 Changes in mean required daily narcotic dose in $\mathrm{mg}$ (morphine equivalent) of 34 patients over time (at baseline, 2 weeks, 2 months, and 3 months). Error bars indicate $95 \%$ confidence intervals.

To date, several studies separately examined celiac neurolysis and splanchnic neurolysis for cancer-related pain of the upper abdomen. ${ }^{24,25} \mathrm{~A}$ study compared radiofrequency ablation and chemical neurolysis of splanchnic nerve, and found better outcomes with the former. ${ }^{26}$ However, very few studies directly compared splanchnic vs celiac neurolysis so far. ${ }^{18,20,27}$ Some reported better analgesic efficacy, reduced opioid use, decreased frequency of complications, as well as improved quality of life with splanchnic nerve neurolysis as compared to celiac plexus neurolysis. ${ }^{18,27}$ In addition, splanchnic block was found to be associated with longer pain relief effect when compared to celiac plexus block in chronic abdominal pain not related to cancer. ${ }^{28}$ In the retrospective study by Koyyalagunta et al, the involvement of the celiac plexus was not a factor that altered the efficacy of splanchnic neurolysis. ${ }^{20}$ The anatomy of the celiac plexus may undergo significant changes due to underlying malignant condition or enlarged celiac lymph nodes in patients with advanced cancer, leading to challenges in accessing the celiac ganglia or inadequate diffusion of the neurolytic agent. ${ }^{15-17}$

Side effects observed in our study included selflimiting hypotension and diarrhea/increased stool frequency, in addition to temporary neuritis in one patient; and we believe that such effects may be considered minor complications/side-effects. Again, these observations strongly suggest that fluoroscopy-guided splanchnic neurolysis is a safe as well as an effective therapeutic option.

Several other methods other than chemical neurolysis target celiac plexus/splanchnic nerve and/or other structures for pain relief. High intensity focused ultrasound (HIFU) technology seems to be an attractive alternative because it is a non-invasive and safe technique that provides rapid pain relief; in addition, it has been used successfully after failed celiac plexus neurolysis. ${ }^{29-31}$ Endoscopic ultrasound-guided celiac plexus neurolysis (EUS-CPN) and EUS-guided celiac ganglion radiofrequency ablation are other techniques with promising results in patients with pancreatic cancer pain. ${ }^{32-34}$ The latter technique was found to be superior to celiac plexus neurolysis in terms of pain relief and improvement in the quality of life. ${ }^{32}$ Spinal cord stimulation may be another option for these patients, but evidence regarding efficacy is lacking. ${ }^{35,36}$ One of the valuable options for the palliative treatment of cancer pain in general, pancreatic cancer pain in particular, is the intrathecal or epidural port catheter use for opioid or local anesthetic administration, which 
represents an effective method for the end-of-life care of these patients. ${ }^{37-39}$ Although many studies have reported successful results with mechanical splanchnicectomy, ${ }^{40,41}$ this procedure may also lead to serious complications such as pneumothorax, chylothorax, spleen injury, and intercostal neuralgia. ${ }^{42}$ Finally, bilateral splanchnicectomy with thoracotomy may be considered in patients who require abdominal surgery for other reasons; thereby there will be no additional surgical risk for the patient. ${ }^{41}$ Nevertheless, team expertise and availability should also be kept in mind while selecting the appropriate technique for a particular patient.

The minimum time required to achieve pain relief after celiac neurolysis shows some degree of variability, with some studies reporting immediate pain control and others reporting a more delayed onset of efficacy. ${ }^{43,44}$ In our study, a significant pain relief was achieved 2 weeks after the procedure. Although previous studies showed an increased rate of survival after splanchnic neurolysis, ${ }^{45}$ we have not been able to evaluate such an effect on survival due to the short follow-up duration, ie 3 months.

In a study by Ischia et al comparing several approaches including splanchnic, classic retrocrural, and trans-aortic techniques, the incidence of hypotension was shown to be higher with the retrocrural (50\%) and splanchnic (52\%) approach as a result of sympathetic neurolysis, while anterocrural transaortic technique led to increased defecation more frequently $(65 \%) .{ }^{46}$ With regard to other temporary complications, all three groups exhibited similar rates of hematuria, hiccups, inter-scapular back pain, reactive pleurisy, and dysesthesia. ${ }^{46}$ In addition, gastroparesis and gastric perforation, as well as retroperitoneal fibrosis have been reported. ${ }^{46}$

Celiac and splanchnic neurolysis are associated with very few complications, and these include hypotension, diarrhea, gastric or intestinal perforation, vessel injury, hematoma, and chemical peritonitis. ${ }^{47}$ Due to the absence of anatomical structures in the close adjacency of the splanchnic nerve that may lead to complications other than pneumothorax, neurolysis of the nervous tissue at this site is rarely associated with the above-stated complications. The reported rate of orthostatic hypotension and increased defecation after a diagnostic block was $23 \%$ in the study by Ahmed A. et al, where splanchnic block and neurolysis were administered to the study participants. In that study, $19 \%$ and $14 \%$ of the patients reported orthostatic hypotension and increased defecation, respectively. ${ }^{17}$ On the other hand, in a study by
Shwita $\mathrm{AH}$ et al the respective incidences of orthostatic hypotension and increased defecation were 33\% and $29 \%$, and $34 \%$ and $30 \%$ in celiac and splanchnic neurolysis groups, respectively. ${ }^{27}$ Fourteen patients $(36.8 \%)$ experienced orthostatic hypotension in our study group, and this complication resolved on the same day in all patients. Again, nine patients experienced temporary diarrhea/increased defecation in our study, and in only one case the complaints required medical treatment and lasted 1 week. Except for moderately severe neuritis that resolved spontaneously in a few days, no patients experienced serious complications in our study.

Major limitations of our study include retrospective design and limited duration of follow up. Since overall changes over time and pairwise differences between baseline and other time points reached statistical significance, the relatively small sample size does not seem to be a major limitation; however, a larger sample size would be able to show differences between 2 weeks, 2 months and 3 months, if any. Although there are alternative and more comprehensive methods to access pain in general, cancer pain in particular, such as numerical rating scale (NRS), Brief Pain Inventory (BPI), ${ }^{48}$ McGill Short Form Questionnaire, ${ }^{49}$ Alberta Breakthrough Pain Assessment Tool, ${ }^{50}$ the current study used only VAS for the purpose of evaluation owing to its ease and simplicity, which may be considered another limitation.

In conclusion, splanchnic neurolysis seems to provide durable pain control and reduced opioid use in patients with upper abdominal pain due to pancreatic cancer in whom the neurolysis of the celiac plexus was unable to control the pain. Therefore, this method represents a viable option for this group of patients. On the other hand, the procedure needs well-trained stuff; thus, it may not be available in many hospitals. It is of note to emphasize that our conclusions refer to only preliminary singlecenter results in a selected patient group; thus, further randomized studies with larger sample size, in different patient groups, and with longer follow-up are warranted to confirm our findings.

\section{Ethics Committee Approval}

The study protocol was approved by local ethics committee (Date, December 16, 2019; no, 44140529/482). The study was conducted in accordance with the Declaration of Helsinki. All patient data accessed complied with relevant patient data protection and privacy regulations. 


\section{Author Contributions}

The author made a significant contribution to the work reported in the areas of conception, study design, execution, acquisition of data, analysis and interpretation, and in drafting, revising and critically reviewing the article; gave final approval of the version to be published; has agreed on the journal to which the article has been submitted; and agrees to be accountable for all aspects of the work.

\section{Disclosure}

The author reports no funding and no conflicts of interest for this work.

\section{References}

1. Bray F, Ferlay J, Soerjomataram I, Siegel RL, Torre LA, Jemal A. Global cancer statistics 2018: GLOBOCAN estimates of incidence and mortality worldwide for 36 cancers in 185 countries. CA Cancer J Clin. 2018;68(6):394-424. doi:10.3322/caac.21492

2. Freelove R, Walling AD. Pancreatic cancer: diagnosis and management. Am Fam Physician. 2006;73(3):485-492.

3. Moore JC, Adler DG. Celiac plexus neurolysis for pain relief in pancreatic cancer. J Support Oncol. 2009;7(3):83-90.

4. World Health Organization. Cancer Pain Relief. Geneva, Switzerland: World Health Press; 1986.

5. World Health Organization. Cancer Pain Relief with a Guide to Opioid Availability. 2nd ed. Geneva, Switzerland: World Health Organization; 1996.

6. Collins D, Penman I, Mishra G, Draganov P. EUS-guided celiac block and neurolysis. Endoscopy. 2006;38(9):935-939. doi:10.1055/ s-2006-944734

7. Michaels AJ, Draganov PV. Endoscopic ultrasonography guided celiac plexus neurolysis and celiac plexus block in the management of pain due to pancreatic cancer and chronic pancreatitis. World J Gastroenterol. 2007;13(26):3575-3580. doi:10.3748/wjg.v13.i26.3575

8. Schmulewitz N, Hawes R. EUS-guided celiac plexus neurolysistechnique and indication. Endoscopy. 2003;35:S49-S53.

9. Eisenberg E, Carr DB, Chalmers TC. Neurolytic celiac plexus block for treatment of cancer pain: a meta-analysis. Anesth Analg. 1995;80 (2):290-295. doi:10.1097/00000539-199502000-00015

10. Patt RB, Cousins MJ. Techniques for neurolytic neural blockade. In: Cousins MJ, Bridenbaugh PO, editors. Neural Blockade. 3rd ed. Philadelphia: JB Lippincott; 1998:1007-1061.

11. Mercadante S, Nicosia F. Celiac plexus block: a reappraisal.. Reg Anesth Pain Med. 1998;23(1):37-48. doi:10.1016/s1098-7339(98)90109-2

12. Polati E, Finco G, Gottin L, Bassi C, Pederzoli P, Ischia S. Prospective randomized double-blind trial of neurolytic coeliac plexus block in patients with pancreatic cancer. Br J Surg. 1998;85 (2):199-201. doi:10.1046/j.1365-2168.1998.00563.x

13. Kawamata M, Ishitani K, Ishikawa K, et al. Comparison between celiac plexus block and morphine treatment on quality of life in patients with pancreatic cancer pain. Pain. 1996;64(3):597-602. doi:10.1016/0304-3959(95)00189-1

14. Mercadante S. Celiac plexus block versus analgesics in pancreatic cancer pain. Pain. 1993;52(2):187-192. doi:10.1016/0304-3959(93) 90130-H

15. De Cicco M, Matovic M, Balestreri L, Fracasso A, Morassut S, Testa V. Single-needle celiac plexus block: is needle tip position critical in patients with no regional anatomic distortions? Anesthesiology. 1997;87(6):1301-1308. doi:10.1097/00000542-199 712000-00007
16. De Cicco M, Matovic M, Bortolussi R, et al. Celiac plexus block: injectate spread and pain relief in patients with regional anatomic distortions. Anesthesiology. 2001;94(4):561-565. doi:10.1097/ 00000542-200104000-00006

17. Ahmed A, Arora D. Fluoroscopy-guided neurolytic splanchnic nerve block for intractable pain from upper abdominal malignancies in patients with distorted celiac axis anatomy: an effective alternative to celiac plexus neurolysis - a retrospective study. Indian J Palliat Care. 2017;23(3):274-281. doi:10.4103/IJPC.IJPC_28_17

18. Ozyalcin NS, Talu GK, Camlica H, Erdine S. Efficacy of coeliac plexus and splanchnic nerve blockades in body and tail located pancreatic cancer pain. Eur J Pain. 2004;8(6):539-545. doi:10.1016/j.ejpain.2004.01.001

19. Zaza C, Baine N. Cancer pain and psychosocial factors: a critical review of the literature. J Pain Symptom Manage. 2002;24 (5):526-542. doi:10.1016/S0885-3924(02)00497-9

20. Koyyalagunta D, Engle MP, Yu J, Feng L, Novy DM. The effectiveness of alcohol versus phenol based splanchnic nerve neurolysis for the treatment of intra-abdominal cancer pain. Pain Physician. 2016;19(4):281-292.

21. Burton AW, Phan PC, Cousins MJ. Treatment of Cancer Pain: Role of Neural Blockade and Neuromodulation. Philadelphia: Lippincott Williams and Wilkins; 2009.

22. Molloy R, Benzon H. Neurolytic Blocking Agents: Uses and Complications. Philadelphia, PA: Mosby Elsevier; 2008.

23. Raj PP. Visceral pain. Agri. 2004;16(1):7-20.

24. Rahman A, Rahman R, Macrinici G, Li S. Low volume neurolytic retrocrural celiac plexus block for visceral cancer pain: retrospective review of 507 patients with severe malignancy related pain due to primary abdominal cancer or metastatic disease. Pain Physician. 2018;21:497-504. doi:10.36076/ppj.2018.5.497

25. Novy DM, Engle MP, Lai EA, et al. Effectiveness of splanchnic nerve neurolysis for targeting location of cancer pain: using the pain drawing as an outcome variable. Pain Physician. 2016;19 (6):397-403.

26. Amr SA, Reyad RM, Othman AH, et al. Comparison between radiofrequency ablation and chemical neurolysis of thoracic splanchnic nerves for the management of abdominal cancer pain, randomized trial. Eur J Pain. 2018;22(10):1782-1790. doi:10. 1002/ejp. 1274

27. Shwita AH, Amr YM, Okab MI. Comparative study of the effects of the retrocrural celiac plexus block versus splanchnic nerve block, $\mathrm{C}$-arm guided, for upper gastrointestinal tract tumors on pain relief and the quality of life at a six-month follow up. Korean $J$ Pain. 2015;28(1):22-31. doi:10.3344/kjp.2015.28.1.22

28. Kapural L, Lee N, Badhey H, McRoberts WP, Jolly S. Splanchnic block at T11 provides a longer relief than celiac plexus block from nonmalignant, chronic abdominal pain. Pain Manag. 2019;9 (2):115-121. doi:10.2217/pmt-2018-0056

29. Anzidei M, Marincola BC, Bezzi M, et al. Magnetic resonance-guided high-intensity focused ultrasound treatment of locally advanced pancreatic adenocarcinoma: preliminary experience for pain palliation and local tumor control. Invest Radiol. 2014;49 (12):759-765. doi:10.1097/RLI.0000000000000080

30. Zhou Y. High-intensity focused ultrasound treatment for advanced pancreatic cancer. Gastroenterol Res Pract. 2014;2014:205325. doi:10.1155/2014/205325

31. Dababou S, Marrocchio C, Rosenberg J, et al. A meta-analysis of palliative treatment of pancreatic cancer with high intensity focused ultrasound. J Ther Ultrasound. 2017;5(1):9. doi:10.1186/s40349-0170080-4

32. Bang JY, Sutton B, Hawes RH, Varadarajulu S. EUS-guided celiac ganglion radiofrequency ablation versus celiac plexus neurolysis for palliation of pain in pancreatic cancer: a randomized controlled trial (with videos). Gastrointest Endosc. 2019;89(1):58-66 e3. doi:10.10 16/j.gie.2018.08.005 
33. Minaga K, Takenaka M, Kamata K, et al. Alleviating pancreatic cancer-associated pain using endoscopic ultrasound-guided neurolysis. Cancers. 2018;10:50.

34. Si-Jie H, Wei-Jia X, Yang D, et al. How to improve the efficacy of endoscopic ultrasound-guided celiac plexus neurolysis in pain management in patients with pancreatic cancer: analysis in a single center. Surg Laparosc Endosc Percutan Tech. 2014;24(1):31-35. doi:10.1097/SLE.0000000000000032

35. So M, Bansal N, Piracha MM. Neuromodulation and Pancreatic Cancer Pain. J Palliat Med. 2018;21(8):1064-1066. doi:10.1089/ jpm.2018.0109

36. Peng L, Min S, Zejun Z, Wei K, Bennett MI. Spinal cord stimulation for cancer-related pain in adults. Cochrane Database Syst Rev. 2015; CD009389.

37. Bruel BM, Burton AW. Intrathecal therapy for cancer-related pain. Pain Med. 2016;17(12):2404-2421. doi:10.1093/pm/pnw060

38. Smyth CE, Jarvis V, Poulin P. Brief review: neuraxial analgesia in refractory malignant pain. Can J Anaesth. 2014;61(2):141-153. doi:10.1007/s12630-013-0075-8

39. Burton AW, Rajagopal A, Shah HN, et al. Epidural and intrathecal analgesia is effective in treating refractory cancer pain. Pain Med. 2004;5(3):239-247. doi:10.1111/j.1526-4637.2004.04037.x

40. Jones WB, Jordan P, Pudi M. Pain management of pancreatic head adenocarcinomas that are unresectable: celiac plexus neurolysis and splanchnicectomy. $J$ Gastrointest Oncol. 2015;6(4):445-451. doi:10.3978/j.issn.2078-6891.2015.052

41. Lahoud MJ, Kourie HR, Antoun J, El Osta L, Ghosn M. Road map for pain management in pancreatic cancer: A review. World $J$ Gastrointest Oncol. 2016;8(8):599-606. doi:10.4251/wjgo.v8. i8.599
42. Masuda T, Kuramoto M, Shimada S, et al. Splanchnicectomy for pancreatic cancer pain. Biomed Res Int. 2014;2014:941726. doi: $10.1155 / 2014 / 941726$

43. Jain $\mathrm{S}$. The role of celiac plexus block in intractable upper abdominalpain. In: Racz GB, editor. Techniques of Neurolysis. Boston: Kluwer Academic; 1989:161.

44. Staats PS, Kost-Byerly S. Celiac plexus blockade in a 7-year-old child with neuroblastoma. J Pain Symptom Manage. 1995;10 (4):321-324. doi:10.1016/0885-3924(95)00014-P

45. Lillemoe KD, Cameron JL, Kaufman HS, Yeo CJ, Pitt HA, Sauter PK. Chemical splanchnicectomy in patients with unresectable pancreatic cancer. A prospective randomized trial. Ann Surg. 1993;217(5):447-457. doi:10.1097/00000658-199305010-00004

46. Ischia S, Ischia A, Polati E, Finco G. Three posterior percutaneous celiac plexus block techniques. A prospective, randomized study in 61 patients with pancreatic cancer pain. Anesthesiology. 1992;76 (4):534-540. doi:10.1097/00000542-199204000-00008

47. Davies DD. Incidence of major complications of neurolytic coeliac plexus block. J R Soc Med. 1993;86(5):264-266.

48. Daut RL, Cleeland CS, Flanery RC. Development of the Wisconsin Brief Pain Questionnaire to assess pain in cancer and other diseases. Pain. 1983;17(2):197-210. doi:10.1016/0304-3959(83)90143-4

49. Melzack R. The short-form McGill pain questionnaire. Pain. 1987;30 (2):191-197. doi:10.1016/0304-3959(87)91074-8

50. Hagen NA, Stiles C, Nekolaichuk C, et al. The alberta breakthrough pain assessment tool for cancer patients: a validation study using a delphi process and patient think-aloud interviews. J Pain Symptom Manage. 2008;35(2):136-152. doi:10.1016/j.jpainsymman.2007.03.016
Journal of Pain Research

\section{Publish your work in this journal}

The Journal of Pain Research is an international, peer reviewed, open access, online journal that welcomes laboratory and clinical findings in the fields of pain research and the prevention and management of pain. Original research, reviews, symposium reports, hypothesis formation and commentaries are all considered for publication. The manuscript management system is completely online and includes a very quick and fair peer-review system, which is all easy to use. Visit http:// www.dovepress.com/testimonials.php to read real quotes from published authors. 